\title{
AC 2010-2171: PROFESSIONAL DEVELOPMENT FOR SCIENCE, TECHNOLOGY, AND MATHEMATICS TEACHERS
}

\section{Kenneth Hunter, Tennessee Technological University}

Kenneth Hunter is an Associate Professor in the Basic Engineering Program at Tennessee Technological University, where he received his BSME and MSME. He is active in engineering education outreach and has over thirty-five years of engineering experience, including positions in academia, industry, the United States Army, and his own consulting business. He is a registered engineer in Tennessee.

\section{Jessica Matson, Tennessee Technological University}

Jessica Matson is a Professor of Industrial and Systems Engineering at Tennessee Technological University. She received her BSIE from Mississippi State University and MSIE and PhD from Georgia Tech. She has been active in engineering education outreach at Tennessee Tech, as well as in prior service on the faculty of Mississippi State and the University of Alabama. She is a registered PE, a member of the EAC of ABET, and 2008-10 ASEE PIC 1 Chair.

\section{Margaret Phelps, Tennessee Technological University}

Margaret Phelps is Assistant Director of the Millard Oakley STEM Center and Professor Emeritus in the College of Education at Tennessee Technological University. She has eight years of experience as a high school math and science teacher and thirty-four years of experience as a faculty member in instructional leadership, science education, and rural education.

\section{Roy Loutzenheiser, Tennessee Technological University}

Roy Loutzenheiser is a Professor of Civil Engineering and Associate Dean in the College of Engineering at Tennessee Technological University. He received his BSCE from Ohio State University, MSCE from Georgia Tech and PhD from Texas A\&M University. He has been in engineering education at Tennessee Tech since 1989, and was formally associated with Purdue University and the University of Maryland. He is a registered engineer in Tennessee. 


\title{
Engineering Professional Development for Science, Technology, and Mathematics Teachers
}

\begin{abstract}
This paper summarizes the objectives, structure, results, and lessons learned from two MathScience Partnership (MSP) programs that have provided engineering-based professional development to science, technology, and mathematics teachers in grades 7 to 12 . The partnerships have included two universities, a technical community college, and more than twenty school districts. The first program (2004-2007) included approximately fifty teachers from over a dozen rural school districts in the Upper Cumberland region of Tennessee. The second program (2008-present) includes sixty intervention teachers and sixty control teachers from eighteen, primarily rural, school districts from across the State of Tennessee. The engineering content of these programs has been prepared and delivered by College of Engineering faculty; instructional technology and pedagogy content has been provided by College of Education faculty; and master teachers have assisted participants in connecting the engineering content with Tennessee curriculum standards and integrating it into classroom lessons. In addition to content knowledge, the programs have provided extensive equipment and materials for classroom instruction, demonstrations, and hands-on activities.
\end{abstract}

Evaluation data from these programs include teacher surveys, classroom observations, content knowledge acquisition by the teachers, and standardized test performance by their students. The second program was designed as a randomized trial research effort and includes data for a matching group of control teachers and their students. Results from both programs have been very positive and include the following:

- Teachers in the both programs have demonstrated gains in engineering knowledge.

- Students of teachers in the first program demonstrated improved performance on standardized achievement tests.

- Statistically significant results of classroom observations conducted during the second program show that students of the intervention teachers demonstrated a variety of higher order learning and thinking skills as compared to the students of the control teachers. Intervention teachers were also observed to make more frequent use of instructional technology and engineering content in their lessons.

- Both programs have received excellent overall ratings from teacher surveys.

In addition, numerous lessons learned are presented, including issues related to logistics management for a state-wide teacher professional development program, collection of teacher and student test data, and program revisions as a result of teacher feedback. 


\section{Introduction}

During the past six years, the Colleges of Engineering and Education at Tennessee Technological University have worked together in two Math-Science Partnership (MSP) grant programs focused on providing engineering professional development content and resources to middle and high school teachers. The first MSP program (EMSP1) was conducted from 2004 to 2007 for approximately fifty math and science teachers from more than a dozen rural school districts in the Upper Cumberland region of Tennessee. Entering its final year, the second program (EMSP2) includes science, math, and technology teachers, with sixty intervention and sixty control teachers from eighteen, primarily rural, school districts across the state of Tennessee. This paper first presents the professional development model that served as the basis for program design and then summarizes the objectives, structure, results, and lessons learned from the two MSP programs.

\section{The Professional Development Model}

Professional development experiences for both MSP programs were based on research on how students and their teachers learn about science, technology, engineering, and mathematics (STEM). Some of the background information specific to engineering education was taken from research conducted by SEEK-16 (Strategies for Engineering Education K-16) participants developing a Pre-AP engineering program. Consideration was also given to research related to teaching and learning in rural and economically disadvantaged environments.

To provide equity of educational opportunity in rural schools serving economically disadvantaged students, one must move from "equity as a separate concept" to "high quality includes all." Challenging students with real-world problem-solving from the world of engineering addresses different learning styles and provides a context for the application of math and science theory that appeals to students of poverty. ${ }^{2}$

Teachers must be scientifically literate and have the necessary tools to engage their students in quests for understanding of engineering concepts. ${ }^{3,4,5}$ Teachers with more content knowledge are better questioners and discussion leaders and are able to identify conceptual patterns and apply those patterns in instruction. ${ }^{6,7}$ If teachers are going to incorporate inquiry and engineeringbased content and activities in their teaching, they must themselves experience learning through inquiry, collaborate with other teachers, have access to and competence in using technology, and have experience with engineering. ${ }^{8,9}$

The interdisciplinary nature of engineering merges laboratory, field, and classroom inquiry with historical and cultural perspectives and the technology in the students' worlds. ${ }^{10}$ Effective classroom practices include conceptual understanding, thinking skills, inquiry, cooperative learning, graphic organizers, computer simulations, actual observation, clear objectives, and ongoing feedback. ${ }^{11}$ Students develop deeper understanding when they generate and test hypotheses, compare and contrast, summarize, and apply prior knowledge. ${ }^{12}$

Operationally the professional development in both programs consisted of 60 hours of summer institute instruction by faculty in the College of Engineering and the College of Education and 
two follow-up Saturday workshops each spring and fall. The emphasis was on hands-on learning using a variety of engineering and instructional technology to collect, analyze, and share data to describe engineering phenomena. Master teachers facilitated communication between institute faculty and participants and conducted the sessions in which participants developed instructional materials for their own classrooms that integrated engineering principles with math and science curriculum standards. Between meetings, teachers were encouraged to collaborate with the faculty and fellow participants by e-mail, invite engineering faculty to their classrooms to serve as resource teachers and talk about careers in engineering, bring groups of students to campus for tours and activities, and prepare their students for engineering-based competitions.

In the era of No Child Left Behind, school districts evaluate all professional development activities on the extent to which they support the implementation of curriculum standards. The project team provided orientation for the engineering faculty on mathematics and science standards and encouraged them to develop their institute sessions in alignment with those standards. To further enhance the standards-based emphasis of the project, master teachers in both mathematics and science conducted sessions throughout the summer institute during which the participating teachers developed their own lesson plans utilizing information and tools from the project that were more finely aligned with specific curriculum standards. These lesson plans were published on the web in PowerPoint format to be available to all teachers in the project.

The approach used in the two MSP programs is supported by the results of a 2009 study by the National Academy of Engineering (NAE).

"Ad hoc infusion, or introduction, of engineering ideas and activities (i.e., design projects) into existing science, mathematics, and technology curricula is the most direct and least complicated option, because implementation requires no significant changes in school structure. The main requirements would be (1) willingness on the part of teachers and (2) access to instructional materials. Ideally, teachers would also have a modicum of engineering pedagogical content knowledge to deliver the new material effectively. The ad hoc option is probably most useful for providing an introductory exposure to engineering ideas rather than a deep understanding of engineering principles and skills." ${ }^{\prime 3}$

Furthermore, the NAE report states that ". . . increasing the visibility of technology, and, especially, engineering in STEM education in ways that address the interconnections in STEM teaching and learning could be extremely important. . . Because of the natural connection of engineering education to science, mathematics, and technology, it might serve as a catalyst for achieving this vision" of STEM literacy for all high school graduates. ${ }^{13}$

\section{EMSP1 - Objectives and Structure}

The goal of the initial partnership was to provide secondary science and mathematics teachers with the knowledge, skills, and materials to integrate the teaching of engineering principles with the Tennessee science and mathematics curricula in grades $7-12$. Specifically, the project was evaluated on the extent to which: 
- Teachers demonstrated increased science, math, and engineering content knowledge on faculty-developed tests administered at the beginning and end of each summer institute.

- Students enrolled in the teachers' classes demonstrated higher achievement on standardized tests of math and science knowledge.

- Teachers initiated field trips, resource speakers, and student competitions related to project activities.

The EMSP1 summer institutes were conducted during two-week periods in June of each year. Teachers commuted daily and averaged six hours per day of training. Participants were divided into three groups: high school science teachers, high school math teachers, and middle school science and math teachers. The groups rotated through three sessions daily. The groupings allowed the institute faculty to tailor the sessions to the needs of each group and allowed greater faculty-participant interaction. Meals and snacks were furnished as part of the program, which also provided opportunities for interaction among participants and faculty.

The project director, responsible for all administrative and fiscal management of the project, was the Associate Dean of Engineering. He recruited faculty from the College of Engineering to serve as institute faculty and made the facilities and equipment of the College available. Engineering faculty prepared and presented all of the engineering sessions during the summer institutes and follow-up Saturday workshops.

The project co-director, a secondary science education faculty member from the College of Education, was responsible for development of partnership relationships with the local education agencies (LEAs), recruitment of participants, and collection of student achievement data for the project evaluation. She also recruited faculty from the College of Education to serve as institute faculty. Education faculty prepared and presented sessions on the mathematical basis for upcoming engineering sessions and the use of web-based instructional materials in teaching engineering concepts. They also reinforced the standards alignment focus of the project.

Tennessee Tech is located in a rural area with a population that is economically disadvantaged. The educational level of the surrounding counties is low. The LEAs are struggling to provide quality educational opportunities in the absence of adequate funding and community support for education. Tennessee Tech provides the initial licensure programs for most of the teachers in the region and, increasingly, provides much of the content-driven professional development for teachers. The instructional leaders in the LEAs are generally supportive of TTU's efforts to attract external funding to provide regional professional development particularly in the middle grades and high school content areas. When the decision was made to apply for an MSP grant, twelve of the LEAs in a fifty mile radius signed on as partners providing letters of support and needs assessment data for the proposal. An instructional leader in each of these LEAs was named as LEA liaison and became the contact person for recruitment, implementation, and evaluation. One of the critical duties of the LEA liaisons was to provide access to project staff and/or participating teachers to the state's restricted student achievement data site so that the required evaluation could be completed.

Working through the LEA liaisons, teachers were recruited for the project. Each year there was some attrition with new teachers added to replace those that resigned from the project for any 
reason. Approximately fifty math and science teachers for grades $7-12$ were actively involved for the entire three years of the project.

The limited technology-based instructional materials available in most of the schools of participating teachers focused the selection of activities and materials. The MSP grant program specifies that funds cannot be used to purchase classroom sets of materials but can be used to obtain single units that participants use in the project for their own professional development and then use in their classrooms for demonstration purposes. In some schools, there were enough participating teachers that they were able to combine their equipment for classroom use. In others, participating teachers were able to convince local administrators or obtain grant money to purchase additional units.

The basic equipment purchased for each participant was a Vernier LabPro data acquisition interface and a Texas Instruments graphing calculator. Project faculty then selected the Vernier sensors that were appropriate for their topics. During the first summer institute in 2005 the LabPro, a selection of sensors, and calculator were distributed and training conducted on their operation. As participants attended subsequent sessions, various additional sensors were distributed and used. Manuals from Vernier for selected middle grades and high school science and math courses were purchased for the teachers so they could do activities beyond those led by project staff. During the summer institutes in 2006 and 2007, participants also received Lego® Mindstorms robotics kits, small electronics toolkits, and digital multimeters.

\section{EMSP1 - Evaluation and Results}

Participant Response. The participating teachers responded positively to the interaction with engineering faculty and vice versa. At first the teachers were reluctant to provide feedback directly to the engineering faculty. They would share their concerns with the master teachers who then conveyed the feedback to the faculty in afternoon debriefing sessions. Comments ranged from "Dr. X is awesome!" to "Tell Dr. Y not to ever do that again!" By the third year the engineering faculty had adjusted their instruction to meet the teachers' needs and the teachers had begun to provide feedback directly to the faculty. Their feedback also became more directed and spontaneous. The engineering faculty came to appreciate the teachers' knowledge of how students learn, the workload of the teachers, and the effort of the teachers to learn and add to their teaching. One teacher initiated an annual field trip of all high school students to campus with presentations by faculty in engineering and other STEM disciplines. Other teachers brought classes to campus for field trips or invited engineering faculty to their classrooms.

Teacher Content Knowledge. Engineering faculty submitted questions each spring to be compiled into a content knowledge test for the summer institute. The questions were designed to measure knowledge and skills that the engineering faculty were planning to teach in their sessions. Consequently, a different test was used each year. The teachers took the test the first morning of the summer institute and again the last afternoon of the institute. In each year of the project, teachers demonstrated substantial gains from pre-test to post-test. Figure 1 shows the results for the fifty teachers in the final summer institute, whose scores increased from $45.6 \%$ to $74.0 \%$. These results were typical of all three years of the program. 


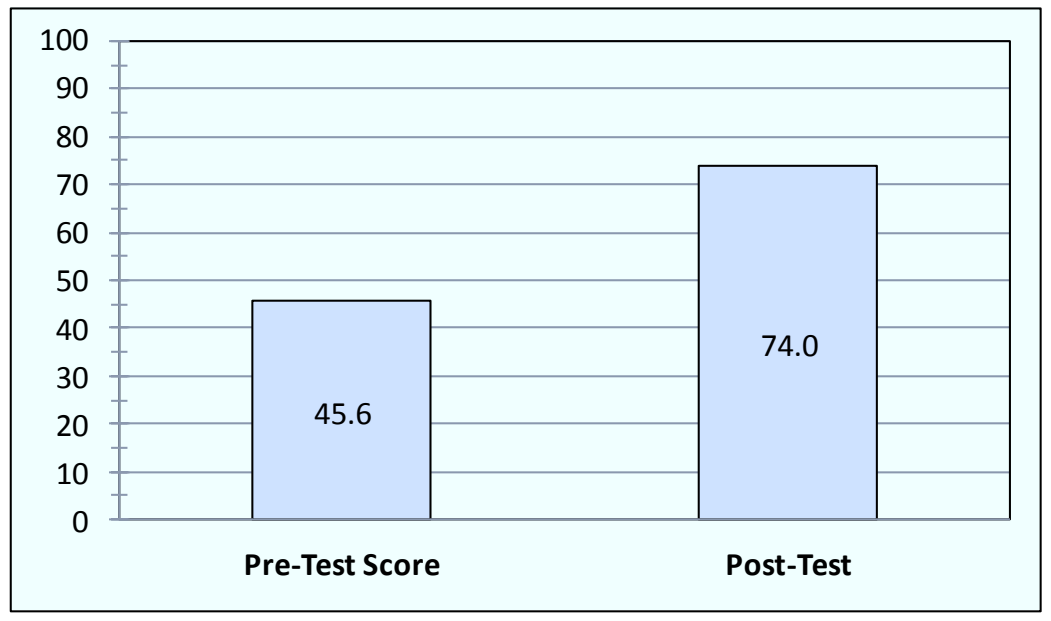

Figure 1. EMSP1 Summer Institute Teacher Engineering Content Knowledge - Year 3

Student Achievement Scores. The required analysis of student data consisted of pre/post comparisons of student scores on state math and science assessments for the year before they were in a class taught by a project teacher and for the year during which they were taught by project teachers. For middle school students, NCE scores (normal curve equivalent scores with a mean of 50 and standard deviation of 21) and proficiency levels on the Tennessee Comprehensive Achievement Program (TCAP) test were collected and analyzed. For high school students, proficiency levels on their most recent state achievement test were used for the baseline. Proficiency levels for the various Gateway (required pass for graduation) and end-ofcourse tests that each student had taken were collected and sorted by subject.

The data in Figures 2 and 3 are reflective of student outcomes for the project. The data show that the greatest gain by students was in moving from proficient to advanced. This result is indicative of raising the bar of content and problem-solving within the existing science and math curricula.

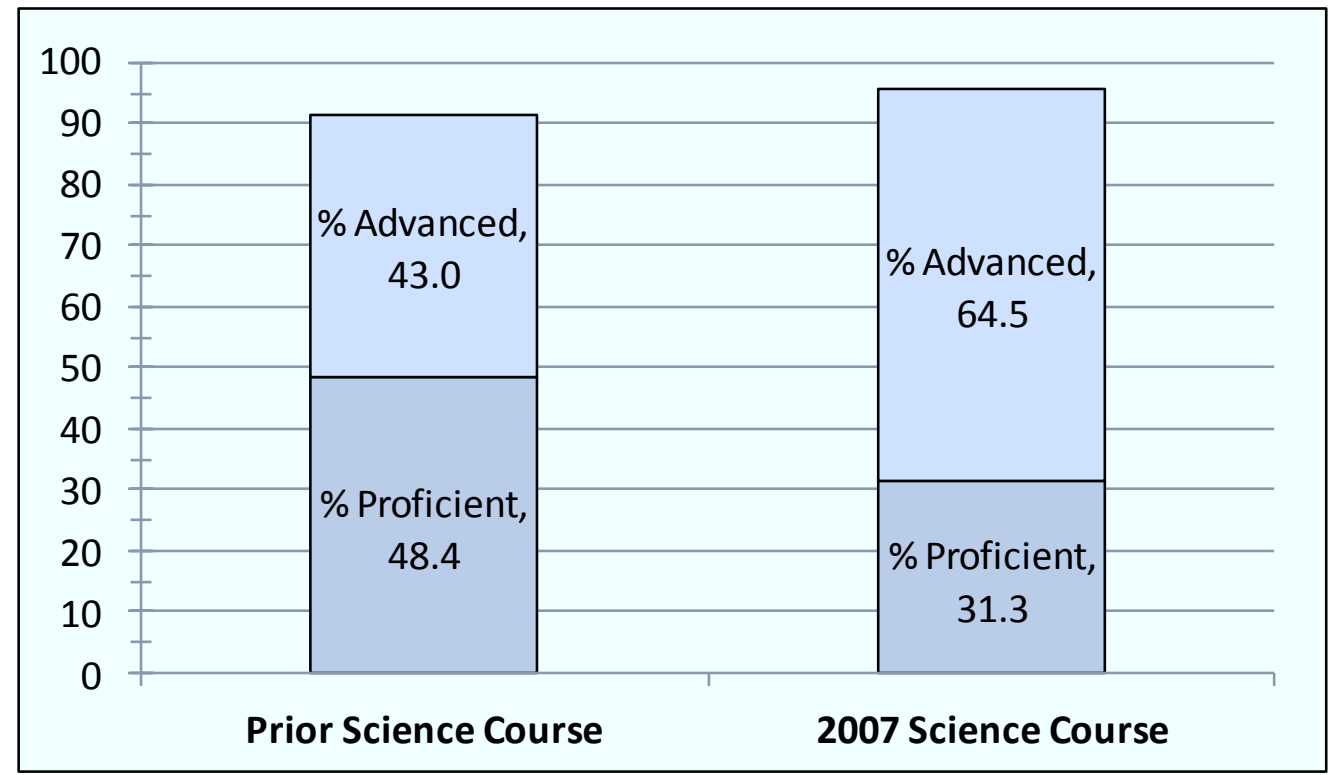

Figure 2. EMSP1 Student Science Achievement - Year 3 


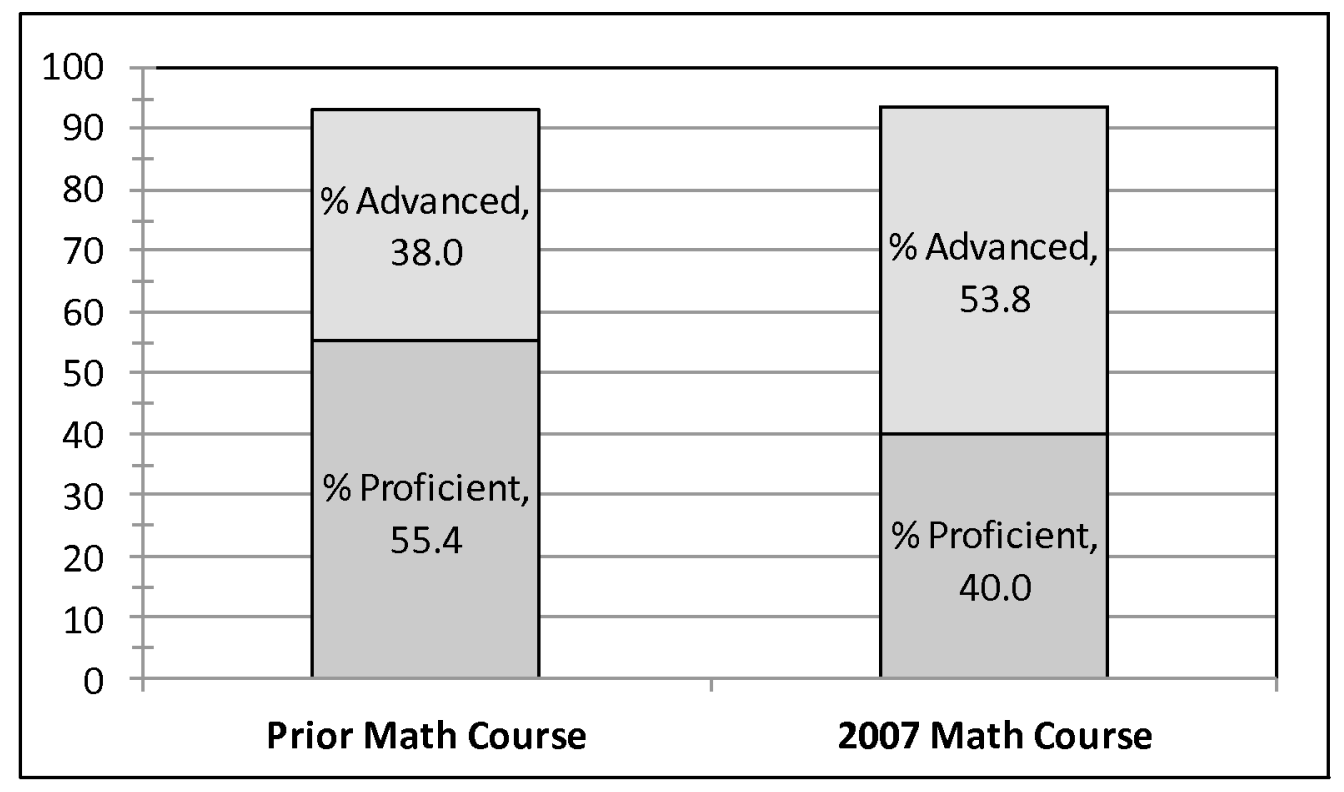

Figure 3. EMSP1 Student Math Achievement - Year 3

\section{EMSP2 - Objectives and Structure}

Given the feedback from the participating teachers and the promising results of EMSP1, the project team applied for a second Engineering Math Science Partnership grant. The EMSP2 program differs from the first in the following ways:

- Participants include career technical teachers as well as grades $7-12$ math and science teachers.

- There is a matched set of control teachers to allow comparisons. Both intervention and control teachers were randomly assigned.

- A test developed by an external agency is being used to measure teacher content gains. The same test will be used all three years.

- Classroom observations have been added to the data being collected.

- The project is statewide to broaden its impact.

Like the EMSP1 program, the goals of the EMSP2 project focus on increased teacher content knowledge of math, science, and engineering and increased student achievement in math and science. Greater emphasis has been placed on teachers' use of technology in their classrooms.

The statewide scope of the EMSP2 program necessitated the addition of two higher education partners. Northeast State Technical Community College in east Tennessee and the University of Tennessee at Martin in west Tennessee provide facilities for Saturday workshops and engineering faculty contacts for regional support during the school year. The two faculty members participate in the summer institutes as well.

The EMSP2 summer institutes have been conducted during seven-day periods in July. The seven-day format, Sunday afternoon through Saturday noon, was adopted to reduce the 
inconvenience to teachers who live too far away to commute. Teachers at the summer institute are housed in a university residence hall, and all meals are provided. Some teachers from the Upper Cumberland region choose to commute. The grant requires sixty hours of training during the summer institute, resulting in ten-hour workdays on Monday through Friday. This format has proven very popular with the majority of the participants and was critical for the successful recruitment of teachers from other parts of the state. Likewise, in consideration of teachers in different regions of the state, each Saturday workshop is repeated on each of the three higher education partner campuses on three different Saturdays.

Participants have again been divided into three groups for rotating through the technical sessions during the summer institutes. The groups for EMSP2 are science teachers, math teachers, and career technical teachers. A different grouping is used for team design projects, however. Teams are organized by school system so that math, science, and career technical teachers are participating on the same design team. This interaction has resulted in informal support networks and enhanced collaborations during the school year.

Technical sessions, led by College of Engineering faculty, have been organized to focus on at least four engineering disciplines each year. In addition to technical sessions, the EMSP2 program has included speakers and field trips to provide a more complete understanding the engineering profession. Field trips have included a research institution (Vanderbilt Institute for Nanoscale Science and Engineering), a manufacturer of automation systems (Automation Tool Company), and a state-of-the-art cancer treatment facility (Cookeville Regional Medical Center).

The project director for EMSP2 participated as an engineering faculty member in all three years of the EMSP1 program. The project co-director from the EMSP1 program continued in her role.

Many of the local LEAs who participated in EMSP1 continued, but the statewide scope required extensive recruiting to secure participation of LEAs in more distant regions of the state. A total of eighteen LEAs committed to the program with 120 teachers.

At the beginning of the project, the local evaluator did a random selection and assignment to intervention and control from each partner LEA. After the LEAs were notified of the placement of their teachers, several requests were received from LEAs to change the assignments. Those requests were honored, leaving the program with 53 randomly assigned intervention teachers and 53 randomly assigned control teachers out of each group of 60 . The teachers who were changed were designated as "administrative" placements. Resignations, teacher reassignments, and other factors have resulted in some attrition, leaving 51 randomly assigned teachers in the intervention group.

As noted previously, the use of instructional technology is a major emphasis of EMSP2. The basic equipment purchased for each participant during the first two years includes a tablet PC, multimedia projector, document camera, digital camera, Vernier LabQuest data acquisition unit, selection of Vernier sensors, Parallax Boe-Bot, small toolkit, digital multimeter, and numerous other items. Manuals from Vernier, an introductory engineering textbook for high school students, and other curriculum materials have also been provided. 


\section{EMSP2 - Evaluation and Results}

Participant Response. Surveys conducted after each summer institute and Saturday workshop have produced uniformly positive results. All aspects of the project, from technical sessions to logistical and administrative functions, have received very strong ratings. Perhaps the best indicator, however, is the reported frequency of use of program content and technology in the classroom. Table 1 shows the reported results during the school year following the first summer institute.

Table 1. EMSP2 Teacher Use of Program Content and Technology - Year 1

\begin{tabular}{|l|c|c|c|c|c|}
\hline \multicolumn{1}{|c|}{ Resource Usage } & None & $\begin{array}{c}1-5 \\
\text { times }\end{array}$ & $\begin{array}{c}6-10 \\
\text { times }\end{array}$ & $\begin{array}{c}11-20 \\
\text { times }\end{array}$ & $\begin{array}{c}21+ \\
\text { times }\end{array}$ \\
\hline Using project content & $0 \%$ & $22 \%$ & $27 \%$ & $12 \%$ & $33 \%$ \\
\hline Using project instructional strategies & $0 \%$ & $14 \%$ & $18 \%$ & $33 \%$ & $31 \%$ \\
\hline Using document camera for lesson presentation & $4 \%$ & $10 \%$ & $10 \%$ & $14 \%$ & $55 \%$ \\
\hline Using digital camera for lesson preparation & $4 \%$ & $29 \%$ & $20 \%$ & $22 \%$ & $20 \%$ \\
\hline Using Vernier equipment in lesson & $8 \%$ & $24 \%$ & $20 \%$ & $22 \%$ & $22 \%$ \\
\hline Using tablet PC and projector in teaching & $0 \%$ & $4 \%$ & $6 \%$ & $4 \%$ & $82 \%$ \\
\hline Using other project materials & $2 \%$ & $16 \%$ & $16 \%$ & $18 \%$ & $47 \%$ \\
\hline Talking to my students about engineering & $0 \%$ & $8 \%$ & $10 \%$ & $29 \%$ & $49 \%$ \\
\hline
\end{tabular}

Teacher Content Knowledge. Teacher content knowledge is measured in EMSP2 using the ASSESS instrument published by the Junior Engineering Technical Society (JETS). The ASSESS instrument contains three sections: mathematics reasoning, science reasoning, and practical understanding (engineering). Although the instrument was designed to evaluate the interest and overall aptitude of potential engineering students, it was selected because it was the only instrument found that represented a collaborative effort of a nationwide group of engineers and educators.

The equivalence of the intervention and control teacher groups was evaluated using the first administration of the test. The null hypothesis was that there were no differences in the prior knowledge of math, science, and engineering between the intervention and control groups. Using a two-tailed t-test for unequal variances and a .05 level of significance, neither math nor science nor engineering scores were determined to be different for the intervention and control groups. However, the p-values in science and engineering were only slightly above the .05 level of significance and the results were significantly different when the combined scores for all three test sections were compared. Table 2 summarizes the results of the evaluation, which reflects test results for 51 intervention (I) teachers and 43 control (C) teachers.

Unfortunately, random selection did not yield truly equivalent intervention and control groups in terms of teacher content knowledge as reflected by test scores. Considering this finding, the analysis of program results focused on teacher content knowledge gains rather than absolute teacher knowledge level. 
Table 2. Equivalence Evaluation for Intervention and Control Groups Based on First Test Scores

\begin{tabular}{|c|c|c|c|c|c|c|c|c|}
\hline \multirow{2}{*}{ Test } & \multicolumn{2}{|c|}{$\begin{array}{c}\text { Math } \\
\text { (max. score = 25) }\end{array}$} & \multicolumn{2}{c|}{$\begin{array}{c}\text { Science } \\
(\text { max. score = 34) }\end{array}$} & \multicolumn{2}{c|}{$\begin{array}{c}\text { Engineering } \\
(\text { max. score = 25) }\end{array}$} & \multicolumn{2}{c|}{$\begin{array}{c}\text { Total } \\
\text { (max. score = 84) }\end{array}$} \\
\hline Group & I & C & I & C & I & C & I & C \\
\hline Mean & 16.4 & 14.9 & 26.3 & 23.2 & 18.3 & 16.5 & 60.9 & 54.6 \\
\hline Variance & 27.6 & 40.7 & 39.8 & 70.0 & 16.4 & 23.3 & 124.6 & 280.8 \\
\hline P-Value & \multicolumn{2}{|c|}{0.214} & \multicolumn{2}{c|}{0.052} & \multicolumn{2}{c|}{0.064} & \multicolumn{2}{c|}{0.038} \\
\hline
\end{tabular}

Teacher content knowledge gains resulting from their program experience through the end of the second summer institute are summarized in Table 3. Gains are measured by subtracting a teacher's initial test score from the most recent post-test score. The null hypothesis was that the gains of intervention teachers would equal the gains of control teachers. The alternate hypothesis was that the gains of intervention teachers would exceed the gains of control teachers. Using one-tailed t-tests for unequal variances and a .05 level of significance, intervention teachers were found to have significantly higher gains in science and engineering but not in math. These results were not unexpected since the program content of the first two years was more focused on science and engineering. (A stronger focus on mathematics is being considered for the final year.) The gains were also significantly higher for intervention teachers when considering the combined scores. This evaluation is based on the same sets of intervention and control teachers as represented in Table 2.

Table 3. Teacher Knowledge Gain Evaluation for Intervention and Control Groups

\begin{tabular}{|c|c|c|c|c|c|c|c|c|}
\hline Test & \multicolumn{2}{|c|}{ Math } & \multicolumn{2}{c|}{ Science } & \multicolumn{2}{c|}{ Engineering } & \multicolumn{2}{c|}{ Total } \\
\hline Group & I & C & I & C & I & C & I & C \\
\hline Mean & 1.47 & 0.60 & 2.86 & -0.60 & 1.84 & -0.12 & 6.18 & -0.12 \\
\hline Variance & 8.29 & 20.91 & 15.92 & 43.67 & 7.41 & 16.44 & 39.55 & 136.34 \\
\hline P-Value & \multicolumn{3}{|c|}{0.143} & \multicolumn{2}{c|}{0.002} & \multicolumn{2}{c|}{0.004} & \multicolumn{2}{c|}{0.001} \\
\hline
\end{tabular}

Note: Gain $=2009$ Post-Test Score - First Test Score

Teacher Classroom Performance. Teacher classroom performance is evaluated using the Kentucky Science and Technology Consortium Science Classroom Observation Protocol modified for Engineering. Classroom observations have been completed for the 2008-09 school year, the year following the first EMSP2 summer institute. The findings are summarized as follows.

1. The use of technology-based presentation media was already greater in fall of 2008 for the intervention teachers who had attended the first summer institute in July 2008. The use increased during the year. In addition, the proportion of times technology based presentation media was observed throughout the year was significantly higher ( $p$-value = .0027) for the intervention group than the control group.

2. In evaluating questioning techniques used by teachers in the classroom, intervention teachers were found to ask questions that "stimulated higher order and divergent thinking" and to encourage students to ask questions at significantly higher rates of occurrence (p-values of 0.0013 and 0.0620 , respectively) than the control teachers. 
3. The classroom culture of the intervention teachers increased from fall of 2008 to spring of 2009 in curiosity, confidence, accuracy, enthusiasm, critical thinking, persistence, objectivity, and responsibility. In addition the overall rate of occurrence of confidence, enthusiasm, critical thinking, and objectivity was significantly higher ( $p$-values of 0.0456 , $0.0089,0.0485,0.0057$, respectively) for the intervention teachers than for the control teachers.

4. The development of identified pre-engineering skills and delivery of content related to first principles of engineering demonstrate that intervention teachers are taking the content back to their classrooms. The skills of observing, classifying, modeling, and basic computer skills had significantly higher overall rates of occurrence (p-values of $0.0032,0.0062,0.0442,0.0281$, respectively) for intervention teachers than for control teachers.

5. In terms of the overall classroom profile, the intervention teachers had significantly higher rates of effectiveness for all students ( $p$-value of 0.0009), defined objectives fully aligned with standards ( $\mathrm{p}$-value of 0.0089), and all students engaged in activities requiring high level thinking skills (p-value of 0.0362) than did control teachers. The overall profile of intervention teacher classrooms was more positive than for control teacher classrooms.

Student Achievement Scores. To evaluate student achievement gains in math and science, the plan was to conduct pre/post comparisons of student scores on state math and science assessments for the year before they were in a class taught by a project teacher and for the year during which they were taught by project teachers. Table 4 summarizes the EMSP2 assessment data collected. Analysis has been complicated by the introduction of new state curriculum standards and a recalibration of standardized test scores between the pre and post assessments. The scaling of state standardized tests was adjusted to increase rigor and bring Tennessee standards in line with national standards. These changes have made it difficult to draw meaningful conclusions although analysis is ongoing.

Table 4. EMSP2 Assessment Data for Evaluating Student Achievement Gains

\begin{tabular}{|c|c|c|}
\hline Subject Area & Middle School & High School \\
\hline Math and Science & $\begin{array}{c}\text { NCE scores } \\
\text { TCAP proficiency levels }\end{array}$ & ACT projected percentiles \\
\hline Engineering & $\begin{array}{c}\text { JETS ASSESS } \\
\text { (engineering understanding) }\end{array}$ & $\begin{array}{c}\text { JETS ASSESS } \\
\text { (engineering understanding) }\end{array}$ \\
\hline
\end{tabular}

To evaluate engineering knowledge gains, students of intervention and control teachers are compared on their pre- and post-test scores on the engineering understanding portion of the JETS ASSESS instrument. The same test is used each time with items re-sequenced. Only paired scores are used in reporting. The JETS ASSESS results for the first year of the EMSP2 program indicate that there is no statistically significant gain in engineering understanding for either the intervention or control teachers' students. This result is not surprising because the engineering content of the EMSP2 program does not specifically address the test items. 


\section{Lessons Learned and Conclusions}

There have been numerous lessons learned during the five years of the EMSP1 and EMSP2 projects, including the following.

- The use of a variety of teacher groupings during the summer institute was found to be beneficial. Groupings by content area allowed institute faculty to focus their content on the needs of each group and allowed teachers to collaborate and share ideas and lesson plans with other teachers in the same content area. Groupings by LEA for team design projects promoted team-building within the school system and the development of informal support networks during the school year.

- Recruiting for a statewide project was a challenge. Although TTU has enjoyed a close relationship with the school districts in the local Upper Cumberland area, the university has typically not offered programs in other regions of the state. Extensive recruiting activity was necessary to obtain viable teacher groups in both east and west Tennessee. A benefit of this effort is new relationships and support, which will make it easier to recruit for future programs.

- The use of a seven-day, sixty-hour summer institute for EMSP2 has proven to be a success. This schedule was implemented to make the program more attractive for teachers who live too far away to commute daily. The vast majority of teachers and institute faculty have expressed satisfaction with this approach, even though it requires long days.

- A major success has been the use of classroom observations in both intervention and control teacher classrooms. The results obtained from these observations have been very positive and have provided important information about the impact of the program that would have otherwise been missed.

- A major challenge has been the timely collection of teacher and student test data for a statewide project. Online pre/post testing of teachers was used during the first year of the project. Software and Internet access issues created significant problems with this approach. For the second year, paper tests and scan forms have been used. The major challenge during the second year has been getting control teachers to respond to testing requests in a timely manner. Timely administration and collection of student pre-/posttests has also been a problem as teachers contend with busy classroom schedules and other required testing.

- The field trips added as part of the EMSP2 program have proved to be very effective in helping teachers understand what engineers do and how engineering impacts their lives.

In summary, the professional development model used in EMSP1 yielded very positive results in teacher content knowledge gains and student achievement gains. However, the lack of teacher and student control groups limited the conclusions that could be drawn from the study. Building 
on the professional development model of the first program and using randomly selected intervention and control groups, the EMSP2 program has shown statistically significant gains in teacher content knowledge and improvements in classroom instruction. Although state changes in curriculum standards and standardized testing have hampered efforts to determine student achievement gains, we are optimistic that gains will be demonstrated during the remaining year of the program.

\section{Acknowledgements}

The authors would like to thank the Tennessee Department of Education and, in particular, Dr. Scott Eddins, for support of both programs. We also want to thank the summer institute faculty, staff members, and student assistants who have participated in these projects. Finally, we want to thank the many teachers and school system administrators who have worked with us.

\section{Bibliography}

1. Campbell, P. and N. Kreinberg, Moving into the Mainstream: From Equity as a Separate Concept to High Quality for All. American Association for the Advancement of Science, 1998.

2. Payne, R., A Framework for Understanding Poverty. Highlands, TX: aha! Process, Inc., 1998.

3. American Association for the Advancement of Science, Project 2061, Benchmarks for Science Literacy. American Association for the Advancement of Science, 1993.

4. Brooks, J. and M. Brooks, In Search of Understanding: The Case for Constructivist Classrooms. Alexandria, VA: Association for Supervision and Curriculum Development, 1993.

5. Donovan, M., J. Bransford, and J. Pellegrino, How People Learn: Bridging Research and Practice. National Academies Press, 1999.

6. Druva, C. and R. Anderson, "Science Teacher Characteristics by Teacher Behavior and by Student Outcome: A Meta-Analysis of Research," Journal of Research in Science Teaching, Volume 20, Issue 5, 1983.

7. Cawelti, G. (editor), Handbook of Research on Improving Student Achievement, 2nd edition. Arlington, VA: Educational Research Service, 1999.

8. Committee on Science and Mathematics Teacher Preparation, National Research Council, Educating Teachers of Science, Mathematics and Technology: New Practices for the New Millennium, National Academies Press, 2000.

9. Wenglinsky, H., How Teaching Matters: Bringing the Classroom Back into Discussions of Teacher Quality. Princeton, NJ: Educational Testing Service, 2000.

10. Loucks-Horsley, S., P. W. Hewson, N. Love, and K. E. Stiles, Designing Professional Development for Teachers of Science and Mathematics. Thousand Oaks, CA: Corwin Press, 1998.

11. Marzano, K, D. Pickering, and J. Pollock, Classroom Instruction that Works: Research-based Strategies for Increasing Student Achievement. Association for Supervision and Curriculum Development, 2001.

12. National Commission on Mathematics and Science Teaching for the 21 st Century, Before It's Too Late: A Report to the Nation from the National Commission on Mathematics and Science Teaching for the $21^{\text {st }}$ Century. U. S. Department of Education, 2000.

13. Katehi, L., G. Pearson, and M. Feder (editors), Engineering in K-12 Education: Understanding the Status and Improving the Prospects. National Academies Press, 2009. 